\title{
¿Demócratas en La Mancha? En torno a los orígenes de la cultura política republicana en Castilla-La Mancha $(1854-1868)^{\star}$
}

\author{
JUAN ANTONIO INAREJOS MUÑOZ \\ Universidad de Castilla-La Mancha
}

\section{Democrats in La Mancha? Around the origins of the republican political culture in Castilla-La Mancha (1854-1868)}

\begin{abstract}
RESUMEN
Los argumentos resultantes del estudio de las formas de acción política, respaldo social, componentes culturales y organización desplegada por el Partido demócrata en unas provincias eminentemente agrarias y rurales como las que en la actualidad integran Castilla-

La Mancha, constituyen las mejores herramientas para derrumbar algunos de los tópicos historiográficos que han presentado al republicanismo como un fenómeno de exclusivo arraigo en espacios urbanos o industriales y a las zonas rurales del interior peninsular como apolíticas, desmovilizadas y dominadas por el conservadurismo.
\end{abstract}

PALABRAS CLAVE:

Reinado Isabel II, Partido demócrata, republicanismo, formas de acción política, politización rural.

\section{ABSTRACT}

The arguments, which result from the analysis of the political plans of action, social support, cultural components and organization spread by the Democratic Party over some especially farming and rural provinces like those which make up Castilla-La Mancha nowadays, are the best tools to demolish some of the historiographic topics which have defined republicanism as an event of restrictive influence on urban and industrial places and the rural areas of the peninsular interior as non-political areas, demobilized and ruled by the conservatism.

\section{KEYWORDS:}

Queen Isabel II reign, Democratic Party, republicanism, political plans of action (policy-policies), rural politicization.

* Investigación realizada en el marco del Proyecto BHA 2003-06215 del MEC dirigido por el prof. Juan Sisinio Pérez Garzón, a quien agradezco las orientaciones prestadas para la confección de este trabajo, adelanto de una tesis doctoral en ciernes. 
En general, ha constituido un lugar común en la historiografía la consideración de las zonas rurales del interior peninsular como apolíticas, desmovilizadas y dominadas por el conservadurismo, prejuicios que en la actualidad, como han advertido diversos autores, requieren importantes matizaciones a tenor de la filtración del ideario demócrata-republicano más allá de las zonas urbanas y de la periferia peninsular, sus tradicionales bastiones. ${ }^{1}$

En el caso concreto de la actual Castilla-La Mancha, poco se conoce, por no afirmar prácticamente nada, respecto a las formas de acción política, respaldo social, componentes culturales y organización del Partido demócrata allende el Sexenio democrático -objeto de estudio de este trabajo-, en concordancia con el campo apenas hollado del periodo isabelino. ${ }^{2}$ Salvo algunas manifestaciones aisladas durante los primeros años de la andadura liberal, no es sino a partir de 1854 cuando se tiene un conocimiento relativamente preciso y detallado de la actividad de los primeros demócratas en la región. ${ }^{3}$

\section{DE LOS PRIMEROS ESFUERZOS ORGANIZATIVOS AL RETORNO A LA CLANDESTINIDAD}

Tras la ruptura de 1837, ratificada formalmente en 1849, la experiencia del Bienio marcó de forma rotunda un antes y un después en la estrecha ligazón que hasta esos años había vinculado a progresistas y demócratas. ${ }^{4}$ La zigzagueante y con-

1 Baste recordar a PIQUERAS ARENAS, J. A.:»Introducción: los historiadores y el republicanismo», en Chust, M. y PIQueras ArenAs, J. A. (comps.): Republicanos y repúblicas en España, Madrid, Siglo XXI, 1996, pág. XXXII, quien ha prevenido del error de considerar el republicanismo como un fenómeno exclusivamente urbano; a DUARTE, A. y GABRIEL, P.: «¿Una sola cultura política republicana ochocentista en España? ", Ayer, 39, (2000), pág. 15, autores que han señalado el importante papel que, en el desarrollo del republicanismo decimonónico (principalmente durante el Sexenio y la Restauración), jugó su difusión y arraigo no sólo en las ciudades, sino también en los municipios agrarios, en estrecha relación con uno de sus rasgos definitorios, el localismo (como objetivo de conquistar poderes tangibles); o VILLENA ESPINOSA, R.: «El espejo invertido. Los republicanos e Isabel II», en Pérez Garzón, J. S. (ed.): Isabel II. Los espejos de la Reina, Madrid, Marcial Pons, 2004, pág. 160; quien ha incidido en la adopción del ideario republicano por un sector significativo del campesinado.

2 Al respecto sólo se cuenta con las panorámicas generales aportadas por GonzÁLEZ CALLEJA, E. y Moreno Luzón, J.: Elecciones y parlamentarios. Dos siglos de historia de Castilla-La Mancha, Toledo, Junta de Comunidades de Castilla-La Mancha, 1993, págs. 26-48; y EsteBAn BARAHONA, L.: La I Internacional en Castilla-La Mancha, Madrid, Celeste, 1998, págs. 49-74. El término región es utilizado como herramienta para referirse a las cinco provincias que en la actualidad componen Castilla-La Mancha.

3 Es el caso del falso bulo difundido en otoño de 1821 por los realistas de Ciudad Real y Valdepeñas, según el cual los liberales estaban dispuestos a proclamar una República lberiana, cuya primera acción sería una matanza de clérigos, en CASTRO ALFín, D.: «Orígenes y primeras etapas del republicanismo en España», en Townson, N. (ed.): El republicanismo en España (1830-1977), Madrid, Alianza, 1994, pág. 37; o la creación en Albacete entre 1842 de un diario republicano, El Defensor del Pueblo, SÁNCHEZ SÁNCHEZ, I.: La prensa en Castilla-La Mancha. Características y estructura (1811-1939), Cuenca, Universidad de Castilla-La Mancha, 1991, pág. 90; periódico que, pese a no conservarse ningún ejemplar, evidencia la existencia en la capital albaceteña de un sector social permeable a las ideas republicanas.

4 Azagra Ros, J.: El Bienio Progresista en Valencia. Análisis de una situación revolucionaria a mediados del siglo XIX, Valencia, Universidad de Valencia, 1978, pág. 90. 
tradictoria tarea de gobierno del Ejecutivo presidido por Espartero coadyuvó de manera decisiva al incremento sustancial de las bases de la todavía incipiente democracia castellano-manchega. ${ }^{5}$ Varios frentes de actuación de las nuevas autoridades contribuyeron a cimentar el desengaño demócrata durante estos dos años. Excluidos de las cinco Juntas de Gobierno provinciales establecidas en julio de 1854 (controladas abrumadoramente por propietarios terratenientes), fueron relegados a formar parte de las juntas locales y de los nuevos ayuntamientos revolucionarios, instituciones que, una vez consumado el trasvase de poder, o bien fueron disueltas o sometidas a un proceso de renovación. ${ }^{6}$ Las depuraciones que sufrió la Milicia Nacional con el objetivo de atajar en el seno de la institución el paulatino ascendiente popular, y por ende, republicano, no vinieron sino a dilatar la línea de fractura ya abierta entre progresistas y demócratas. ${ }^{7}$ Las purgas operadas en los batallones de Albacete y Toledo constituyeron un ejemplo acabado al respecto. ${ }^{8}$ No obstante su mayor laxitud, el mantenimiento de los criterios censitarios para acceder al pleno disfrute de los derechos políticos de ciudadanía amordazó al electorado demócrata y contribuyó poderosamente a dejarle privado de sentar representantes en las Constituyentes de 1854, las primeras en las que el sistema monárquico fue abiertamente sometido a discusión.

Al igual que ocurrió en otras zonas, resulta evidente la vinculación establecida entre determinadas personalidades y los primeros esfuerzos organizativos por difundir el ideario demócrata en la región. ${ }^{9}$ Uno de estos pioneros fue el sombrerero conquense Gregorio Sánchez Escribano. Afincado en Ciudad Real desde 1855, fue encarcelado en varias ocasiones por las autoridades locales acusado de propagar abiertamente las ideas republicanas. ${ }^{10}$ Una de las poderosas razones, la represión, que años atrás había influido en la denominación formal del partido como demócrata en lugar de republicano. Dese usted por contento en verse preso y en no ser

\footnotetext{
${ }^{5}$ Resulta sintomática la trayectoria descrita por tres vecinos de Fuentealbilla (Albacete), milicianos y miembros del Partido progresista en 1854, quienes al hilo de las decisiones adoptadas por el Gobierno del Duque de la Victoria, como la salida de María Cristina, abrazaron el republicanismo y comenzaron a desacreditar al partido progresista, tachándole de reaccionario y de otras lindezas por el estilo; El Clamor Público, 13-XI-1856.

6 Sin ánimo de exhaustividad, así ocurrió con la Junta de Gobierno de Caudete, con una importante presencia demócrata, El Clamor Público, 10-VIII-1854; o con los republicanos Mariano Villanueva y Francisco Ruano, designados concejales del Ayuntamiento capitalino por la Junta de Gobierno de Toledo, ulteriormente sustituidos en los cargos tras celebrarse una nueva elección censitaria; Archivo Municipal de Toledo (AMUTO), Actas de plenos, 22-VII-1854 y 2-X-1854.

7 Pérez Garzón, J. S.: Milicia Nacional y revolución burguesa. El prototipo madrileño (1808-1874), Madrid, CSIC, 1978, pág. 481.

${ }^{8}$ Archivo Histórico Provincial de Albacete (AHPAB), Sección Municipios (Albacete), Milicia Nacional, caja 367; y AMUTO, Milicias, caja 1.569

${ }_{9}$ Sirva como ejemplo el protagonismo de Víctor Pruneda en la articulación del núcleo republicano de Teruel, VILLANUEVA HeRreRA, J.: El republicanismo turolense durante el siglo xix: 1840-1898, Zaragoza, Mira, 1993.

10 Rodríguez Solís, E.: Historia del partido republicano español, Madrid, Imp. Domingo del Val, 1893 , t. II, págs. 463 y 553-554. Véase en esta obra un breve repaso de su biografía, que abarca desde su participación como miliciano en la primera contienda carlista hasta su intervención en los sucesos revolucionarios de 1848 en Madrid.
} 
enviado a Filipinas, fueron los argumentos esgrimidos por las autoridades para justificar una de sus detenciones, que, no obstante, no impidieron que diez años más tarde hubiese conseguido estructurar, junto a otros correligionarios de la localidad, el primer Comité democrático en Ciudad Real. ${ }^{11}$

Bajo el prisma del progresismo, tal vez por comparación con la administración anterior, durante los dos años que siguieron a la «Vicalvarada» los demócratas habían gozado de una relativa libertad, tolerancia que en el fondo no fue sino una represión atemperada. El retorno al poder del moderantismo a partir de 1856 suscitó un frontal rechazo, larvado desde el mismo mes de agosto de 1854, ante una posible vuelta a la dominación existente dos años atrás. Levantaron acta del descontento las diferentes partidas republicanas formadas a lo largo de la región. Dos de ellas fueron la organizada por el conquense Froilán Carvajal y Rueda en su provincia natal, ${ }^{12}$ y la capitaneada por los hermanos Merino en los alrededores de Despeñaperros, en suma, bullangueros y minoría facciosa, según el peyorativo y simplista rasero empleado desde la prensa conservadora en un intento por despolitizar los levantamientos. ${ }^{13}$

El sedimento conspirativo, cuyas raíces se hunden en el principio del derecho a la insurrección —de tradicional arraigo en la cultura política republicana—,${ }^{14}$ recobró una posición central a lo largo del segundo tramo del reinado isabelino, explicitado en los distintos planes descubiertos por las autoridades para organizar una partida en «La Mancha» dentro de un marco más amplio definido por las sublevaciones de la primavera-verano de 1857 en Andalucía. ${ }^{15}$ En Villarrobledo, el Gobernador Civil de Albacete registró personalmente las casas de varios demócratas durante el mes de julio a raíz de unos supuestos rumores de conspiración que habían despertado la desconfianza de las autoridades. Las pesquisas resultaron infructuosas, ya que, como se encargaron de asegurar desde la prensa demócrata, los correligionarios de esta localidad estaban interesados en la cuestión de orden

11 La Democracia, 8-IX-1865.

12 Rodríguez Solís, E.: Op. Cit., t. II, pág. 516. Dicha partida fue disuelta una vez conocido el cese de los enfrentamientos en Madrid, Barcelona, Zaragoza y Valencia.

13 La Época, 25-VII-1856; El Diario Español, 25-VII-1856 y 30-VII-1856; y El Clamor Público, 30-VII1856. Según se afirmó desde estos voceros, dicha partida llegó a contar con más de 800 efectivos antes de ser disuelta por el Gobernador Militar de Ciudad Real.

${ }^{14}$ García Rivera, A.: Reacción y revolución en la España liberal, Madrid, Biblioteca Nueva, 2006, pág. 309.

15 El Diario Español, 1-VII-1857, y 18-VII-1857. Según los planes abortados por la Guardia Civil, la supuesta partida debió unirse a la que, organizada en La Carolina, se encargó de cortar la comunicación con Andalucía. Ningún detalle más se aporta acerca de los perfiles concretos que hubiese tomado dicha sublevación en tierras manchegas. Si es conocida la dureza de la represión que sufrieron algunos de sus correligionarios jienenses sorprendidos por las fuerzas gubernamentales, finalmente fusilados por orden de Narváez; Rodríguez Solís, E.: Op. Cit., t. II, pág. 482. Sus principales cabecillas, los hermanos Merino, escaparon a Portugal y organizaron nuevas intentonas durante la década de 1860; ROEL, E.: El partido demócrata español (1849-1868), Madrid, Rialp 1963, pág. 235. En relación a las conspiraciones andaluzas, consúltese MolineR PRADA, A.: «La frustrada insurrección armada republicana de mayo de 1857», en Donézar, J. M. y Pérez Ledesma, M. (eds.): Antiguo Régimen y liberalismo. Homenaje a Miguel Artola, t. 2, Madrid, Alianza, 1995, pág. 571. 
público, encuadrados dentro de la corriente individualista, los llamados demócratas «de orden», frente a la tendencia socialista que fue la que soportó el peso de las sublevaciones en $1857 .{ }^{16}$ Algo similar ocurrió en Consuegra (Toledo) en el instante en que se conocieron los sucesos de Loja en 1861, donde los rumores de conspiración difundidos indujeron a las autoridades a recoger las armas entre el vecindario. ${ }^{17}$

Unos supuestos intentos de sublevación que, al igual que los propalados en 1857, provocaron la alarma y enérgica condena en los diarios conservadores, desde cuyas líneas se mostró una especial satisfacción por la represión gubernamental de los graves atentados cometidos por estas facciones socialistas. ${ }^{18}$ Fórmulas condenatorias que no fueron sino el trasunto de dos de los vectores de la política del doctrinarismo, la estricta observancia del orden público y la defensa de una propiedad a la que presentaron amenazada en un intento por mermar el respaldo social de los demócratas.

De forma paralela a estos planes conspirativos hicieron acto de aparición una serie de manifestaciones esporádicas de republicanismo, que, aunque inconexas y fragmentarias, dejaron testimonio ya desde fechas muy tempranas de la oposición generada contra el entramado de poder tejido por el moderantismo, y, más concretamente, contra su piedra angular, Isabel II:

«Aviso al público...mueran, Fernández, el médico Escuder, el Sacristán, el cura, el cirujano con todos sus secuaces, el maestro de escuela será arrastrado. Viva la República, mueran todos los curas y frailes, abajo la Reina y fuera los Borbones. ${ }^{19}$

El pasquín anónimo, aparecido a comienzos de 1854 en Villaescusa de Haro (Cuenca), constituye el primer testimonio en el que además de cargar contra la reina y su dinastía se colocó a la propia Corona en el punto de mira. Pese a que su fecha de aparición resulta harto sugerente, no se conocen más detalles que permitan reconstruir de forma concisa las motivaciones que coadyuvaron a su gestación. Similar parquedad informativa nos ofrece la noticia aparecida en la prensa unionista sobre los gritos dados a favor de la República en Toledo con motivo de la subida al poder de O'Donnell en 1858. ${ }^{20}$

Mayor interés revisten las muestras públicas de «republicanismo», en virtud de la posibilidad de recomponer las causas y entramado que contribuyeron a su gestación. En abril de 1868, un jornalero de Canalejas (Cuenca), tras conocer que su

16 La Discusión, 26-VII-1857. Para una ampliación de la disputa surgida en el seno del partido a raíz de las sublevaciones republicanas de 1857, véase RoEL, E.: Op. Cit., pág. 235.

17 El Pueblo, 26-VII-1861.

18 El Parlamento, 17-VII-57. En estos términos se expresaron los miembros del Ayuntamiento y mayores contribuyentes de Almadén (Ciudad Real) a través del comunicado de felicitación elevado al Gobierno por la represión del levantamiento de 1857.

19 AHPAB, Audiencia criminal, «Desórdenes públicos», caja 17, causa num. 1.

20 El Diario Español, 5-IX-1858. 
único sobrino había sido declarado soldado, irrumpió en el salón consistorial en el cual se estaba celebrando el sorteo de los mozos e insultó a las autoridades locales antes de cagarse en la reina y manifestar que era una puta. ${ }^{21}$ Un testimonio que demuestra como la espontánea protesta popular ya no era dirigida exclusivamente hacia el sistema de reclutamiento, sino contra los padres de la quinta, desde las autoridades locales encargadas de ejecutar las operaciones hasta la propia cúspide que amparó todo el sistema, Isabel II. Las nuevas medidas implantadas por el Estado liberal estaban impulsando la traslación de actitudes sociales a comportamientos políticos..$^{22}$ En este caso concreto, la de un jornalero soltero y empobrecido de avanzada edad al que se le privó de la única fuente alternativa de ingresos que, en un futuro no muy lejano, debía garantizar su subsistencia. De ahí el potencial republicanismo que entrañaron los insultos proferidos contra la soberana, reveladores a su vez de importantes aspectos de la cultura política popular, caso de la trascendencia y confusión de la vida pública y privada de la soberana, en cuya significación cultural —más allá de los tópicos simplistas vertidos a partir de sus relaciones sentimentales-, también cosechó un reconocido fracaso Isabel II. ${ }^{23}$ Un malestar que fue canalizado por los demócratas incluyendo en su programa la abolición de las quintas y convirtiendo la protesta, durante el Sexenio Democrático, en un movimiento relativamente organizado. ${ }^{24}$

\section{LA INSTITUCIONALIZACIÓN DE LA DEMOCRACIA: COMITÉS Y SOCIEDADES RECREATIVAS}

Con anterioridad al encuadramiento formal en los distintos comités que jalonaron la región mediada la década de 1860 , se puede rastrear el calado del ideario demócrata a partir de las diferentes suscripciones solidarias puestas en marcha desde los órganos periodísticos con el objetivo de socorrer a las familias de destacados correligionarios represaliados. En 1859 fue la respuesta a la llamada del partido para socorrer a la familia del correligionario Tomás Brú, asesinado en Sagunto, ${ }^{25}$ en 1861 el motivo fue la recaudación de fondos para trasladar las cenizas del levantisco Sixto Cámara, ${ }^{26}$ o en 1863 a propósito de la ayuda a las familias de Ruiz Pons y del resto de encausados en Zaragoza por un delito de imprenta, ${ }^{27} \mathrm{co}-$

21 AHPAB, Audiencia criminal, "Desórdenes públicos», caja 17, causa num. 21.

22 Piqueras Arenas, J. A.:»Detrás de la política. República y federación en el proceso revolucionario español», en Chust, M. y Piqueras Arenas, J. A.: Op. Cit., pág. 4.

${ }_{23}$ Villacorta Baños, F.:»Reina, Corte y cortesanos en representación», en Pérez Garzón, J. S. (ed.): Op. Cit., pág. 292.

${ }_{24}$ FEIJOO GómeZ, A.: Quintas y protesta social en el siglo XIX, Madrid, Ministerio de Defensa, 1996, pág. 425.

25 Martínez Gallego, F. A.: Conservar progresando. La Unión Liberal (1856-1868), Valencia, Instituto de Historia Social, 2001, págs. 84-85.

26 Fernández Urbina, J. M.: Sixto Cámara, un utopista revolucionario, Bilbao, Univ. País Vasco, 1984.

${ }_{27}$ Con motivo de la primera de ellas, sirvan como ejemplo las suscripciones abiertas en Almagro, El Bonillo y Minaya (Albacete); La Discusión, 21-II-1859; en Quintanar de la Orden (Toledo), Tobarra (Al- 
lectas cuya respuesta permite evaluar, además de la distribución regional de la prensa demócrata, el sustrato sobre el cual se articulará la posterior red de comités locales.

El final del «Gobierno largo» de O'Donnell supuso un punto de inflexión en la actividad política desplegada por los diferentes núcleos demócratas de la región. Al hilo del debate de las principales cuestiones que afectaron a la línea de actuación del partido, caso del retraimiento electoral, se tejió una tupida red de comités locales y provinciales que vino a suponer una cierta institucionalización de los focos de correligionarios que, siempre bajo la atenta mirada de las autoridades, habían ido adoptando el credo demócrata desde años atrás. El 24 de septiembre de 1865 se celebró en el teatro de Ciudad Real una reunión de más de 400 demócratas de toda la provincia con el objetivo de elegir un nuevo Comité provincial y someter a discusión la política abstencionista. Dicho acto, en el cual también se designó a un miembro que actuaría como su representante en la reunión del futuro Comité central, permite entrever la embrionaria y desconocida estructuración del partido en la provincia a través de la presencia de los comisionados de los distintos subcomités locales. ${ }^{28} \mathrm{El}$ seguimiento que despertó en los diarios de ámbito nacional se explica en virtud de la asistencia de miembros del Comité central y de algunos redactores de los diarios demócratas madrileños, portavoces de las directrices del sentir mayoritario del partido a favor de la prolongación del retraimiento, y, por extensión, de la vía revolucionaria para acceder al poder. La vertebración del foco ciudarrealeño constituye sólo una muestra de una amplia nómina de nuevos comités. ${ }^{29}$

bacete), Alcázar de San Juan (Ciudad Real), Talavera de la Reina, Albacete, Manzanares (Ciudad Real), Guadalajara o Hiendelaencina (Guadalajara); La Discusión, 3-III-1859; 8-III-1859, 10-III-1859, 16III-59, 24-X-1859, 12-III-1859, y 13-III-1859, respectivamente. En relación a la segunda aparecieron suscriptores en Toledo, Talavera y Miguelturra; EI Pueblo, 24-VII-1861 y 22-X-1861. La última de las colectas fue la que menos adhesión despertó, ya que sólo se tienen datos procedentes de Alcázar de San Juan y Toledo; El Pueblo, 16-III-1863. Todas ellas oscilaron entre los 50 y los 200 suscriptores.

${ }_{28}$ La Democracia, 8-IX-1865, y 5-X-1865; El Pueblo, 26-IX-1865, y 28-IX-1865. La cifra de asistentes debe ser tomada con cautela, debido a la frecuente hinchazón de las cifras de asistentes realizada por los diarios demócratas, desde los 400 citados por el primer periódico a los 600 del segundo, prevención que no es óbice para que esté atestiguada la asistencia de un número importante de correligionarios. Según Roel, E., op. cit., p. 313, a la reunión también acudieron correligionarios de Madrid y otras provincias interesados en la continuidad del retraimiento electoral.

29 Sin ánimo de exhaustividad, en relación a la renovación del Comité provincial de Toledo, véase El Pueblo, 2-XI-1865, 16-XI-1865; y La Discusión, 17-XI-1865. Respecto al proceso de formación de la red de comités locales en la región, aparte de los ya citados de Talavera de la Reina, Moral de Calatrava y Almagro, La Discusión, 28-XI-1863 y 15-XI-1863; aparecen, por ejemplo, los de Valdepeñas y Villarrobledo, La Democracia, 1-VI-1864; Albacete y Belmonte (Cuenca), La Democracia, 17-VI-1864; Brihuega (Guadalajara) o Caudete (Albacete), El Pueblo, 8-VIII-1864. En cuanto al número de afiliados las cifras varían en función principalmente del volumen poblacional de las localidades, desde los cuatrocientos que aportan las fuentes para los ya mencionados núcleos de Ciudad Real o Almagro (con las prevenciones realizadas al respecto), a las aproximadamente dos docenas con que por ejemplo contaron las agrupaciones de localidades como Valdepeñas, Villarrobledo, Brihuega, Alcaraz (Albacete) o Caudete, en general pequeñas concentraciones que salpicaron de forma más o menos completa la geografía regional. Demócratas de aldea, según se intituló un correligionario de Quintanar de la Orden (Toledo), pero, al fin y al cabo, demócratas; La Discusión, 26-XI-1863. 
El sustancial incremento del asociacionismo demócrata en la región alentó el tradicional temor del moderantismo a quedar desbancado del poder que había disfrutado de forma casi ininterrumpida desde 1844, inquietud explicitada en un ingenioso artículo que, ya a la altura de 1865 , vislumbró en el horizonte político la inminencia del proceso revolucionario:

«¿Qué haría con estos demócratas manchegos si reapareciese por los campos de Montiel el famoso caballero D. Quijote de la Mancha? De seguro los tomaría por gigantes como a los molinos de viento, y trabaría con ellos la ruda y descomunal batalla que deben trabar los partidos conservadores, hoy mejor que mañana, porque mañana puede ser tarde.»30

En esa descomunal batalla de la que hablaba el artículo anterior entre demócratas y los partidos conservadores, es decir, unionistas y moderados, estos últimos no dudaron en recurrir al tejido represivo proporcionado por el control de las instituciones estatales para entorpecer, cuando no anular, el proyecto político de sus adversarios. La presencia de una sección de la Guardia Civil en Moral de Calatrava (Ciudad Real) en el momento en que se procedía a la elección de un Comité demócrata local, ${ }^{31}$ el arresto del presidente del Comité de Almagro o las trabas impuestas por el Alcalde de Manzanares a varios dirigentes demócratas en el desarrollo de su actividad profesional, ${ }^{32}$ dejan inequívoca constancia del sustrato coercitivo sobre el cual los republicanos tuvieron que desplegar su programa alternativo durante los escasos periodos en que no fueron abiertamente perseguidos. ${ }^{33}$ Una represión que no alcanzó exclusivamente a sus dirigentes u órganos locales, también salpicó a uno de sus principales vehículos transmisores de ideas, la prensa. Más allá de las restrictivas limitaciones formales establecidas en la legislación (depósito previo, jurisdicción de los delitos de imprenta, etc...), las autoridades, conscientes de la trascendental función que desempeñó como agente canalizador de la opinión pública, intentaron expoliar en la medida de lo posible la efectiva distribución de la prensa demócrata madrileña a lo largo de la región. Ocurrió con la cercenada difusión del vocero La Discusión en numerosos pueblos de la provincia de Cuenca tras el retorno de los moderados al poder a finales de 1856, denunciada irónicamente desde las columnas del propio diario; lo más chocante es

30 El Pueblo, 28-IX-1865, artículo recogido del diario moderado La Política, sin fecha.

31 La Democracia, 1-XII-1865.

32 El Pueblo, 13-X-1865, 27-X-1865, 16-XI-1865 y 18-XI-1865; Juan Bautista López era uno de los principales dirigentes demócratas no sólo de Almagro, donde impulsó la creación de un comité local, sino a nivel provincial, como lo atestigua su nombramiento como delegado para representar a la provincia en el Comité central. Fue detenido y encarcelado varias semanas por el juez de primera instancia de Almagro tras denunciar la connivencia de este funcionario con el consistorio neocatólico de la localidad, represión que también le acarreó la confiscación de la gran mayoría de utensilios que poseía en su farmacia. En Manzanares, el primer edil requisó las romanas e instrumentos de peso y medida a un grupo de corredores y pequeños comerciantes de reconocida afiliación demócrata.

${ }_{33}$ Ballbé, M.: Orden público y militarismo en la España constitucional (1812-1983), Madrid, Alianza, 1983, págs. 171-193. 
que sólo los periódicos de oposición son los que se pierden. ${ }^{34}$ Los ejemplos podrían multiplicarse. ${ }^{35}$

De forma paralela al activismo político desplegado en el seno de estos comités se desarrolló una menos conocida sociabilidad informal que tuvo su expresión en la celebración de banquetes, homenajes o recibimientos a destacados dirigentes del partido, verdaderos marcos de socialización y explicitación de fidelidades políticas. Fue el significado que adquirió el recibimiento que los demócratas de Albacete ofrecieron a Emilio Castelar a su paso por la ciudad en 1862, o el banquete que el Comité toledano ofreció a Eugenio García Ruiz, miembro del Comité central y director del periódico El Pueblo, durante su visita a la antigua capital imperial. ${ }^{36}$

Resultaría un error obviar el importante influjo demócrata sobre algunas de las diferentes sociedades recreativas (círculos, casinos, cafés, etc...) que salpicaron la región entre 1854 y 1868, bien al hilo de una mayor liberalización política, como ocurrió durante el Bienio progresista, bien al calor del crecimiento económico experimentado durante los primeros años de la década de los sesenta. A comienzos de 1855 ya existen noticias de la fundación en Toledo de un círculo liberal tras la reunión de más de doscientas personas de todas clases y categorías. ${ }^{37}$ No obstante, no fue hasta comienzos de la década posterior cuando se observe de forma explícita la influencia demócrata en muchas de las sociedades de recreo de nueva fundación. Bajo el control de los demócratas de Quintanar de la Orden (Toledo) se encontraba a la altura de 1863 el casino Círculo de la Amistad, como se encargaron de remarcar a los neocatólicos de la localidad con motivo de las exequias celebradas en honor a Pedro Calvo Asensio. ${ }^{38}$ En abril de 1864 era inaugurada en Ciudad Real una Sociedad Artística con el discurso pronunciado por un dirigente demócrata local. ${ }^{39}$ En estas mismas fechas, era acogida con entusiasmo desde la prensa demócrata madrileña la creación de un Casino Agrícola-artista en Valdepeñas. ${ }^{40}$ Uno de los casinos existentes en Albacete en 1864 se vanagloriaba de intentar procurar a todos (sus socios) solaz, y en especial a la honrada y laboriosa clase artesana, el descanso y esparcimiento que tanto necesita en sus duras y penosas tareas. ${ }^{41}$ Unas sociedades que combinaron este esparcimiento con funciones educativas destinadas al mejoramiento moral y material de las clases menos acomodadas, como se desprende de la actividad desarrollada por el Centro de Artistas e Industriales de Toledo fundado el 14 de marzo de 1866 (y su posterior ca-

34 La Discusión, 25-II-1857.

35 Una justificación bajo el prisma moderado de la censura aplicada a partir de agosto de 1856 a la prensa demócrata, en VALERO Y SOTO, J.: Vindicación del partido moderado español, Madrid, Imprenta M. Sanz, 1856, pág. 22.

${ }_{36}$ El Pueblo, 11-VII-1862 y 30-XII-1864.

37 La Soberanía Nacional, 21-II-1855.

38 La Discusión, 11-X-1863.

39 La Democracia, 13-IV-1864.

40 La Discusión, 12-IV-1864.

41 La Soberanía Nacional, 19-XII-1864. 
sino, dirigido por jóvenes artistas), ${ }^{42}$ la sociedad El Fomento de las Artes de Talavera de la Reina ${ }^{43}$ o por el casino de la localidad toledana de Mora. ${ }^{44}$

A pesar de que todavía es fácilmente diferenciable ese componente pequeñoburgués que definió al propio Partido demócrata desde sus inicios, estas sociedades ejercieron una decisiva influencia en la posterior evolución del denominado asociacionismo de clase desarrollado a partir de la I Internacional. ${ }^{45}$ La estrecha y evidente ligazón existente entre muchas de estas asociaciones con determinados credos políticos, y en este caso concreto con el demócrata, no pasó desapercibida a los ojos de las autoridades gubernamentales que vieron en muchas de ellas una prolongación política de sus respectivos comités locales. ${ }^{46}$ De ahí el especial interés que mostraron por mantenerlas controladas en todo momento, y especialmente a partir de 1865 , cuando arreciaron las conspiraciones revolucionarias. A estas pretensiones respondió la circular de 22 de abril de 1868 que, a instancias del Gobernador Civil, envió el Alcalde de Albacete a los presidentes de los cuatro casinos existentes en la capital con la orden de informar sobre su clase, finalidad, número de socios y la autoridad que había autorizado su establecimiento. ${ }^{47}$ Todos declararon que sus respectivas asociaciones estaban consagradas a la ilustración y el recreo, quedando excluidas en todas ellas las discusiones en torno a temas político-religiosos, como remarcó el Presidente del Casino Artístico en relación a los objetivos de la institución que presidía:

«Proporcionar un rato de solaz distracción a cuantas personas concurren a él, sin que en dicho establecimiento se haya dado todavía el caso de que se traten cuestiones políticas ni otras que tengan más o menos conexión con estas, sin embargo de que esta sociedad se compone de personas de diferentes clases políticas así como también de distinta jerarquía social.»48

Cuán lejos de la realidad. En 1864 la prensa madrileña se había hecho eco de las luchas que tuvieron por escenario este mismo casino entre las diferentes facciones políticas que albergaba en su seno y el control al que los progresistas de Albacete habían sometido a la asociación. ${ }^{49}$ Tampoco es casual que dichas socie-

42 El Tajo, 31-III-1866 y 10-XII-1866.

43 La Conciliación, 28-II-1867; y El Tajo, 3-III-1867.

44 El Tajo, 9-VI-1867.

45 Tanto para el posterior asociacionismo internacionalista en la región como para la cuantificación y labor desarrollada por las sociedades que precedieron a éste, véase Esteban BarahonA, L.: Op. Cit., págs. 59-64.

46 Para la organización interna de estas sociedades y sus dimensiones político-sociales, véase, entre otros, LóPEZ VILLAVERDE, A. y VILLENA ESPINOSA, R.:»Espacio privado, dimensión pública: hacia una caracterización del Casino», Hispania, 214 (2003), especialmente págs. 458-465; MoRALEs MuÑoz, M.: El republicanismo malagueño en el siglo XIX. Propaganda doctrinal, prácticas políticas y formas de sociabilidad, Málaga, Memoria del Presente, 1999, págs. 141-194; y SerRano García, R.: El fin del Antiguo Régimen (1808-1868). Cultura y vida cotidiana, Madrid, Síntesis, 2001, págs. 165-180.

47 AHPAB, Fondo Municipal Albacete, «Estadísticas varias y vecinos sujetos a vigilancia», caja 433.

48 Ibidem.

49 La Soberanía Nacional, 19-XII-1864. También estuvieron representados, en minoría respecto a los progresistas, demócratas, unionistas, moderados e incluso neocatólicos. Desde este diario se criticó el in- 
dades constituyesen la prolongación de unos determinados sectores sociales, como se desprende si se presta atención a las cuotas que aportaron los socios. De nuevo el caso de Albacete constituye un ejemplo acabado. A la altura de 1862 existían dos casinos en la capital, el Primitivo, controlado por los unionistas, y el Artístico, fundado en 1856 y dominado por los progresistas y con presencia demócrata. Si bien se desconoce la extracción social de los integrantes del Casino Primitivo, es innegable que las mayores cuotas de sus afiliados actuaron como elemento de exclusión social frente al menos elitista Casino Artístico, formado mayoritariamente por industriales y clase artesana. ${ }^{50}$ No es gratuito por tanto el interés del Gobernador Civil por controlar estas sociedades recreativas que no eran sino un reflejo de las tensiones políticas y sociales que atravesaron el Albacete prerrevolucionario. En suma, levantaron acta del indisociable vínculo establecido entre sociabilidad cultural, sociabilidad política y sociabilidad recreativa. ${ }^{51}$

\section{CALADO SOCIAL Y SIMBOLOGÍA}

La mejor definición de la base social que constituyó el soporte del partido la proporcionó uno de los vocales del Comité demócrata provincial de Ciudad Real; representaban las diferentes clases que existen en la sociedad. ${ }^{52}$ Las fuentes arrojan un variopinto respaldo que abarcó a profesionales liberales, comerciantes, pequeños propietarios, jornaleros, artistas, y, como no, al idealizado artesano que con el sudor de su frente y su poco o mucho talento, trata de adquirirse el sustento para sí y su numerosa familia. ${ }^{53}$

Las ya aludidas suscripciones promovidas por el partido para socorrer a las familias de correligionarios represaliados aportan valiosos testimonios para profundizar en el conocimiento de su respaldo social. Junto a las ocupaciones con las cuales se autodesignan algunos de los suscriptores (encuadernador, trabajador, sombrerero, aprendiz de artesano, empleado o sastre), aparecen las cantidades donadas por cada uno de ellos, un elemento de diferenciación que permite vislumbrar las desigualdades económicas existentes entre sus simpatizantes. ${ }^{54} \mathrm{Cer}$ -

tento de llevar las luchas políticas a una sociedad recreativa, ataques que no fueron sino la censura del diario a los manejos de un grupo de socios por desplazar a sus correligionarios progresistas de la directiva de la asociación.

50 AHPAB, Fondo Municipal Albacete, «Estadísticas varias y vecinos sujetos a vigilancia», caja 433.

51 GuereÑA, J-L.:»Espacios y formas de la sociabilidad en la España contemporánea. Introducción», Hispania, 214 (2003), pág. 414.

52 El Pueblo, 28-IX-1865.

53 La Discusión, 23-VII-1858.

54 La Discusión, 16-III-1859. Se ha tomado como referencia la suscripción abierta en Ciudad Real para socorrer a la familia del demócrata Tomás Brú. Prácticamente idéntica estructura presentan las suscripciones abiertas en 1863 para socorrer a Ruiz Pons en Alcázar de San Juan y Toledo; El Pueblo, 16III-1863. Es significativo que muchos de los donantes aparezcan con seudónimos o con las iniciales por el miedo a las represalias que podía acarrear identificarse abiertamente con el republicanismo. 
ca de un $80 \%$ de las cantidades donadas estuvieron por debajo de los 4 reales, cantidad próxima al precio estipulado por un jornal diario, ${ }^{55}$ mientras que sólo alrededor de un $10 \%$ superaron la barrera de los 10 reales. Si bien constituiría un error establecer una vinculación mimética entre la cuota aportada y el nivel de renta económica de cada suscriptor, el contraste con otras fuentes refuerza la evidente ligazón trabada entre los principales donantes y una mayor solvencia económica, como ocurrió en el caso del industrial y comerciante republicano Dámaso de Barrenengoa. ${ }^{56} \mathrm{El}$ proceso se repite en relación a los vínculos políticos de los suscriptores. Salvo algunos casos aislados, como el de los progresistas José Sotero o Manuel de Sarachaga en Ciudad Real, resulta palmaria la orientación política de la mayoría de los suscriptores, cuyos nombres figuraron entre los miembros de los Comités demócratas establecidos en sus respectivas localidades. ${ }^{57}$

Al frente de las agrupaciones locales se situó una minoría dirigente integrada por profesionales liberales, pequeños comerciantes y propietarios, es decir, dotada no sólo de una relativa capacidad económica, sino también cultural, al aparecer identificados muchos de ellos como corresponsales de los diarios demócratas madrileños. Dos farmacéuticos encabezaron los Comités de Almagro y Minaya (Albacete),$^{58}$ un grupo de pequeños comerciantes figuró al frente de los demócratas de Manzanares (Ciudad Real), ${ }^{59}$ el propietario y comerciante Mariano Villanueva presidió el Comité toledano, ${ }^{60}$ al igual que ocurrió con el también propietario Ignacio Molero en relación al Comité demócrata arriacense. ${ }^{61}$ Combinaron sus respectivas dedicaciones con la de corresponsales de prensa, es el caso del farmacéutico Juan Bautista Pérez, corresponsal de El Pueblo en Almagro, o simplemente figuraron como suscriptores que informaron a las redacciones de los diarios madrileños de la actividad de las agrupaciones locales y de la represión a la que fueron sometidos en el desempeño de sus actividades profesionales. Sirvan como ejemplo las denuncias realizadas por los anteriores comerciantes demócratas de Manzanares cuando el alcalde moderado les requisó sus romanas e instrumentos de medida, prohibiéndonos el libre ejercicio de la industria de corredores...(y) se

55 Pardo Pardo, M. (coord.): Estructura económica de Castilla-La Mancha (Siglos XVI-XX), Madrid, Celeste, 2000, pag. 106.

56 Constituyó uno de los pocos republicanos que consiguió infiltrarse en las instituciones durante la etapa isabelina, concretamente como concejal del Ayuntamiento ciudarrealeño a partir de 1863; Archivo Municipal de Ciudad Real, Actas de plenos, 1-I-1863. De origen vasco, se estableció en Ciudad Real en 1856, donde creó una industria chocolatera y un establecimiento comercial; La Democracia, 5-X-1865. En relación a su protagonismo político entre 1868 y 1874 como concejal y diputado en las filas republicanas, véase Villena Espinosa, R.: El Sexenio Democrático en la España rural. Ciudad Real (1868-1874), Ciudad Real, Instituto de Estudios Manchegos, 2005, pág. 385.

57 Es el caso del ya mencionado republicano Gregorio Sánchez Escribano, suscriptor junto a sus hijos en la colecta ciudarrealeña, o el de la práctica totalidad de los miembros del ulterior Comité demócrata de Toledo, encabezado por su presidente, Mariano Villanueva, quien aparece en el primer puesto de las donaciones. En relación a los integrantes del Comité toledano, véase La Democracia, 30-VIII-1865.

58 La Discusión, 21-II-1859; y El Pueblo, 13-X-1865.

59 La Democracia, 1-XI-1865.

60 La Democracia, 30-VIII-1865.

61 El Pueblo, 5-VIII-1865. 
atacara directamente nuestra propiedad, o las invectivas que Juan Bautista Pérez dirigió contra el Juez de primera instancia de la localidad tras haberle requisado su instrumental farmacéutico en base a razones políticas.

En contraste con esta minoría dirigente, que podría definirse como medianamente acomodada y detentadora de cierto capital cultural, se encuentra el grueso de los integrantes del partido:

«Difícil parece que bajo la presión tan larga y continuada de los tiránicos poderes que nos han mandado y mandan, se haya podido lograr el que las ideas democráticas desciendan a ilustrar a la masa del pueblo...compuesta esta en su mayor parte de artesanos y jornaleros solo habituados a las faenas del campo y del taller, en nada se resintió de las fórmulas que debía tener,... dando con ello un mentís a los que presumen que por falta de educación política no se halla esta nación dispuesta a recibir tan salvadora doctrina.»62

De forma meridiana muestra el fragmento de un discurso pronunciado con motivo de la renovación del Comité local de Almagro cuál fue el grueso social del partido, artesanos y jornaleros, a pesar de las reconocidas dificultades que entrañó inocular la ideología democrática a esa mencionada masa del pueblo por la falta de educación política, uno de los argumentos utilizados tradicionalmente por el doctrinarismo para cercenar los derechos políticos de la gran mayoría de los ciudadanos. El extracto anterior muestra como existe un interés por dignificar el trabajo realizado artesanos y jornaleros, una idealización que hay que entender dentro de ese culto al pueblo, fuente de toda legitimidad y virtud, que pasó a ocupar un lugar central dentro del discurso republicano. El desdoblamiento de la unidad del concepto de pueblo queda recogido en las palabras del dirigente demócrata almagreño al señalar la dicotomía entre ilustrados, esa minoría activa; e ignorantes, la masa del pueblo; postulando el deber que tenía la primera de ilustrar a la segunda. Un discurso que también recogió el constante recurso a la dualidad entre ese nosotros, los dirigidos; y los dirigentes, los tiránicos poderes que nos han mandado y mandan - saco en el cual entró la Corona-, explicitando el recurrente instrumento de contraponer las elites al pueblo dentro de un marco de agravios comparativos. $^{63}$

El manejo de unos determinados soportes lingüísticos jugó un papel axial en la formación y estructuración de una determinada identidad colectiva, en este caso concreto, de la demócrata-republicana. ${ }^{64}$ No obstante, constituiría un error preterir o discriminar el trascendental papel que desempeñaron los símbolos y componentes culturales a la hora de crear significaciones y actuar como elementos aglu-

62 El Pueblo, 18-XI-1865.

63 CASTRO AlFín, D.: «Jacobinos y populistas. El republicanismo español a mediados del siglo XIX», en Álvarez Junco, J. (comp.): Populismo, caudillaje y discurso demagógico, Madrid, Siglo XXI, 1987, pág. 200.

${ }^{64}$ Cruz, R.: «La cultura regresa al primer plano», en Cruz, R. y Pérez Ledesma, J.: Cultura y movilización en la España contemporánea, Madrid, Alianza, 1997, págs. 24-26. 
tinadores en el seno de las representaciones colectivas. ${ }^{65}$ De ello fueron perfectamente conscientes las autoridades moderadas, quienes se apresuraron a censurar todas aquellas manifestaciones culturales que pudiesen redundar en la cohesión y consolidación de una cultura política republicana.

Durante la celebración en noviembre de 1856 de la toma de posesión del nuevo Ayuntamiento moderado en el municipio conquense de Iniesta, un vecino que recorría las calles del pueblo junto a un grupo de monárquicos puros intentó arrancar el bigote a otro paisano por ser para él y sus compañeros, según públicamente decían, un signo de ideas liberales, un vestigio de la Milicia Nacional. ${ }^{66}$ Aunque muchos de estos aspectos parezcan irónicos o insignificantes, en este caso concreto el dejarse bigote, constituyeron destacados elementos a la hora de conformar una determinada identidad colectiva. Las formas de vestir y modos o modas externas reflejaron actitudes en relación con cuestiones de más calado político. ${ }^{67}$ Más ejemplos. El Alcalde de Quintanar de la Orden prohibió bajo amenaza de multa que una treintena de vecinos exhibiesen públicamente unos gorros encarnados con una borla azul al considerar que encerraban una declarada significación política, y, más concretamente, de constituir un distintivo republicano. ${ }^{68} \mathrm{Al}$ poco tiempo, los mismos individuos compraron unos sombreros de color café oscuro con una cinta de color lila, motivando de nuevo la reacción de la autoridad, en este caso en forma de bando municipal que reprodujo la anterior prohibición, a pretexto también de que tenían significación política, por supuesto la misma que los gorros, medida que fue acompañada con el registro de las casas de varios ex-milicianos de la localidad. Similares hechos tuvieron lugar en la localidad de Almagro, donde en plena precampaña electoral el Alcalde prohibió terminantemente interpretar el popular Himno de Riego. ${ }^{69}$ Bajo el primer mandato unionista fueron encausados varios vecinos de Mota del Cuervo (Cuenca) por tocar el Himno de Garibaldi. ${ }^{70}$ Años antes, en la localidad conquense de Olmedilla del Campo, las coplas que varios milicianos nacionales cantaban en honor a Espartero mientras patrullaban el municipio incitaron a un simpatizante carlista a proferir gritos a favor del pretendiente absolutista. ${ }^{71}$ Los demócratas toledanos fueron presentados como los herederos de los comuneros dentro de ese particular historicismo republicano orientado a ensalzar aquellos episodios de la Historia de España que simbolizaron la lucha contra el absolutismo y la opresión monárquica; Toledo es la patria de Padilla; Toledo es la población que después de la rota, nunca bastante deplorada, de Villalar, alentó a su heroica viuda, la inmortal María de Pacheco. ${ }^{72}$

65 Peyrou, F.: El republicanismo popular en España, 1840-1843, Cádiz, Universidad de Cádiz, 2002, pág. 166.

66 AHPAB, Audiencia Criminal, «Guerras civiles carlistas», caja 62, causa num. 5.

67 Pérez Garzón, J. S.:»Curas y liberales en la revolución burguesa», Ayer, 27, (1997), pág. 86.

68 La Discusión, 1-V-1857.

69 La Discusión, 1-X-1864.

70 Roel, E.: Op. Cit., pág. 267.

${ }^{71}$ AHPAB, Audiencia Criminal, «Guerras civiles carlistas», caja 62, causa num. 3.

72 El Pueblo, 30-XII-1864. 
Este conjunto de símbolos, signos, himnos, coplillas y discursos constituyeron ingredientes de primer orden a la hora de construir representaciones y cohesionar actitudes en torno a un determinado programa político frente a representaciones contrarias (como, por ejemplo, la carlista) y que no pueden ser eludidas a la hora de explicar los factores determinantes que intervienen en la movilización o seguimiento de un determinado proyecto político.

\section{ASPECTOS DOCTRINALES}

Hasta ahora se han combinado los términos demócrata y republicano de forma indiscriminada sin realizar ninguna precisión. Huelga decir que aún siendo prácticamente sinónimos, ambos términos no fueron totalmente asimilables, sin preterir las diferentes corrientes aglutinadas dentro del partido que durante esta etapa vislumbraron ya las importantes divergencias que surgieron en su seno una vez destronada Isabel II, verdadera causa aglutinadora de todas las tendencias con anterioridad a la «Gloriosa». Desborda los objetivos de este trabajo realizar un desglose detallado del programa republicano, cuyos objetivos no quedaron circunscritos a la reforma de la Jefatura del Estado, aunque si resulta conveniente desentrañar (más allá de los comunes principios de reunión, asociación, libertad de prensa, descentralización administrativa, abolición de consumos, etc...), los perfiles concretos que adquirió la democracia castellano-manchega dentro de esa heterogeneidad de corrientes larvadas en el interior de la formación. ${ }^{73}$

Fue la toma de posiciones en relación a la reflotada polémica entre la vertiente socialista (defendida por Pi y Margall desde las páginas de La Discusión), y la vertiente individualista (con Emilio Castelar como principal adalid), el primer y trascendental debate que permite definir ideológicamente con rotunda claridad a los demócratas castellano-manchegos. ${ }^{74} \mathrm{En}$ el marco del desarrollo del conflicto intestino entre «reformistas", inclinados grosso modo hacia la defensa de las asociaciones de trabajadores y reformas complementarias en el orden social; $y$ «republicanos de orden", seguidores de los criterios clásicos del liberalismo económico; los testimonios arrojados por las fuentes indican como la embrionaria democracia de la región se decantó abrumadoramente por la corriente individualista. De hecho, sólo se ha rescatado una manifestación en apoyo de las tesis pimargalianas, en contraste con los numerosos testimonios que, o bien simplemente se posicionaron a favor de los argumentos individualistas, o, además, criticaron en duros términos la corriente socialista. Desde Belmonte se afirmó que dentro de la democracia no podía existir el socialismo porque supondría justificar las acusa-

73 Para profundizar en las diferentes tendencias que confluyeron en la formación del partido, véase RoEl, E.: Op. Cit., págs. 140-141.

74 Para profundizar en el pensamiento de Pi y Margall y el enfrentamiento entre socialistas e individualistas consúltese, entre otras, la ya clásica obra de TRÍAS, J. y ELORZA, A.: Federalismo y reforma social en España (1840-1870), Madrid, Seminarios y Ediciones, 1975, págs. 50-62 y 84-85. 
ciones de comunistas que, desde el bando reaccionario, ${ }^{75}$ se habían realizado con el objetivo de desvirtuarla. ${ }^{76}$ El peligro de escisión para el partido centró el discurso de los demócratas albaceteños, quienes vaticinaron una honda división en el seno de la formación si el director de La Discusión decidía continuar en la defensa de sus postulados. ${ }^{77}$ Otras críticas, procedentes de Toledo, Brihuega, Talavera de la Reina o Caudete, focalizaron el problema en torno a una de las cuestiones centrales de la polémica, la propiedad, y lo absurdo, bajo el prisma individualista, de querernos repartir los bienes del prójimo como defendían las nuevas y disolventes ideas del socialismo irrealizable. ${ }^{78}$

Dos evidentes conclusiones se desprenden de esta serie de testimonios. En primer lugar, dejaron entrever el componente pequeño-burgués que caracterizó desde un primer momento al propio partido, que, en el caso castellano-manchego, vino definido por la condición de pequeños propietarios de muchos de sus correligionarios. También explica que no se halla rescatado ninguna exhortación a una posible redistribución de la propiedad de la tierra o una declarada crítica al proceso desamortizador, consigna que a priori debería haber jugado un trascendental papel dentro del discurso movilizador orientado a la captación de la considerable masa de jornaleros existente en las cinco provincias. Pese a no abogar de forma concisa por la propiedad colectiva de los medios de producción ni la desaparición de las clases sociales (como plantearían poco después los internacionalistas), la imprecisa definición de los socialistas en torno al principio de la propiedad fue aprovechada tanto por el moderantismo como por los propios individualistas —los duros términos de las manifestaciones anteriores constituyen una buena muestra, para presentarlos como declarados enemigos del principal filón de riqueza del momento (la tierra), e intentar cercenar de esta manera su respaldo social. ${ }^{79}$

Frente al abrumador respaldo que despertó la corriente individualista, fueron las doctrinas expuestas por Fernando Garrido y Pi y Margall las que impregnaron las Cartas políticas dirigidas a los electores del distrito de Alcázar de San Juan, escritas por el republicano daimieleño Francisco Córdoba y López en 1864 y publicadas un año más tarde por el diario La Democracia tras haber sido censuradas por el Gobierno Narváez. ${ }^{80}$ El interés de la obra, amén de su recorrido por las principales premisas de la vertiente socialista (defensa de los derechos naturales del hombre, equiparación entre derechos y deberes, sufragio universal, libertad de reu-

75 Es el caso del hermano del Duque de Tetuán, Enrique O’Donnell: La democracia española, Madrid, Imprenta Manuel Minuesa, 1858, pág. 28; o de ILLAS y VIDAL, J.: Un consejo al partido moderado, Madrid, Imprenta Rivadeneyra, 1857, pág. 24.

76 La Democracia, 1-VI-1864.

77 La Democracia, 1-VI-1864. En esta misma dirección estuvo orientada la manifestación procedente de Viso del Marqués (Ciudad Real); El Pueblo, 19-VII-1864.

78 La Democracia, 7-VI-1864, 17-VI-1864 y 22-VI-1864; y El Pueblo, 8-VIII-1864.

79 Castro Alfín, D.: «Unidos en la adversidad, unidos en la discordia: el Partido Demócrata, 18491868», en Townson, N. (ed.): Op. Cit., págs. 78-79.

80 Un sucinto repaso de su carrera política, desarrollada principalmente en Madrid entre 1868 y 1874 , en Esteban Barahona, L.: Op. Cit., págs. 53-55. 
nión y asociación, reconocimiento del derecho a la propiedad, críticas hacia el resto de partidos políticos o programa de reformas sociales), radica en sus denostados y abiertos ataques contra la monarquía (en sintonía con sus convicciones federales), y en la justificación del derecho a la rebelión:

«La resistencia de los pueblos ha sido, en todas las épocas de la historia de nuestra patria, el obstáculo insuperable de los gobiernos absolutos, que han marchado siempre por la senda de la ambición y de la tiranía; y ¿sabéis por qué? porque la suerte de los reyes no ha sido la misma que la de los pueblos que regían...Los reyes se han manifestado sordos ante las exigencias de los pueblos, y la miseria e infortunio de estos ha sido siempre el camino seguido para asegurar la felicidad y aumentar las riquezas de los reyes». .1

El controvertido tema de la religión marcó otra de las líneas de fractura entre creyentes y agnósticos, dentro de la confluencia generalizada en la crítica al clero y una común defensa de la libertad de culto. ${ }^{82}$ Las razones del anticlericalismo demócrata, ese manifiesto rechazo hacia los muchos neos seglares y eclesiásticos,... gente de sotana, que llenaron, con el pesar de un crítico correligionario, las calles de Toledo, se explican a grandes trazos en virtud de la connivencia de la cúpula eclesiástica con la corona y de la enorme influencia que ejerció en cuestiones políticas y culturales tras su progresiva reconciliación con el liberalismo doctrinario. ${ }^{83} \mathrm{~A}$ pesar de los ataques contra los clérigos y el catolicismo, fueron perfectamente conscientes y aprovecharon la potencialidad que abrigó la religión para intentar ganar adeptos a sus filas, más aún al considerar el arraigo de las creencias religiosas en la cultura popular. Los testimonios rescatados evidencian un intento de los demócratas de la región por remarcar en sus proclamas una profesa religiosidad. Así se desprende de las exequias celebradas por los demócratas del casino Círculo de la Amistad de Quintanar de la Orden (Toledo) con motivo del fallecimiento de Calvo Asensio, ocasión que aprovecharon para recordar a los señores neos que los demócratas apreciamos en alto grado los deberes de cristiano ${ }^{84}$ o el clarividente discurso pronunciado por un dirigente local durante la inauguración de una Sociedad Artística demócrata en Ciudad Real:

«...las plegarias llegan al cielo; el fervor religioso comprime todos los corazones, y el Dios de clemencia consuela la ansiedad general, calma y suaviza los temporales, o proporciona soluciones inesperadas a los conflictos, previstas solo por su infinita sabiduría y omnipotencia...Sed religiosos, tened entera fe en la Providencia». ${ }^{85}$

81 La Democracia, 12-VII-1865.

82 Para profundizar en torno a la diversidad de posturas capitalizadas por $\mathrm{Pi}$ y Castelar, véase DuARTE, A.: Història del republicanisme a Catalunya, Vic, Eumo editorial, 2004, págs. 81-83.

${ }_{83}$ El Pueblo, 14-II-1865. Desde este diario se censuraron los ataques lanzados desde la prensa conservadora contra los demócratas toledanos, a quienes acusaron de anticatólicos, cuando en realidad sus críticas apuntaron exclusivamente al estamento eclesiástico.

84 La Discusión, 11-X-1863.

85 La Democracia, 13-IV-1864. En esta misma dirección estuvo orientado el discurso que Eugenio García Ruiz pronunció durante el banquete celebrado por los demócratas toledanos con motivo de su visita a la ciudad; El Pueblo, 30-XII-1864. 
Del fragmento anterior se destila otra de las funciones esenciales que asignaron a la religión, proporcionar soluciones inesperadas a los conflictos, en estrecha relación con el discurso interclasista y armónico desplegado por la mayoría de los demócratas. ${ }^{86}$ No es extraño que tanto neocatólicos como religiosos pusiesen un especial énfasis en meter dentro de un mismo saco el anticlericalismo profesado por sus oponentes con un declarado ataque a la religión, conscientes del seguimiento popular que podía alcanzar un discurso que conjugase las doctrinas democráticas con las creencias religiosas. En este marco conflictual hay que entender las acusaciones vertidas por el alcalde neocatólico de Moral de Calatrava (Ciudad Real) tras irrumpir en el edificio donde se procedía a la formación de un Comité democrático local y acusar a sus miembros de defender la libertad de culto y promover que nuestros hijos quedasen sin bautizar, que fuesen moros y judíos, ${ }^{87}$ o los similares ataques que un sacerdote de Valdepeñas dirigió desde el púlpito, cuyo politizado sermón fue denunciado por un feligrés demócrata:

«Cuando yo esperaba oír sólo palabras de una religión consoladora,...sólo encontré una arenga política contra la democracia. ¡Cuánto más hubiera valido que el Padre atacara a los que llevan la religión en los labios, y no hacen más que torcerla a fines mundanos! $\$ 88$

En el terreno económico, las medidas aprobadas en materia hacendística por los gobiernos moderados resultaron indisociables de su significación política. ${ }^{89}$ Ocurrió con la contribución de consumos, la conocida enajenación de una parte del Patrimonio Real o el empréstito forzoso decretado a comienzos de 1865. Ésta última medida afectó a los contribuyentes que pagasen más de 40 reales de contribución, es decir, a esa "clase media» a la que se refirió un demócrata de Albacete en un comunicado de censura a la ordenanza gubernamental. Dentro de ella englobó a los pequeños comerciantes, los artesanos y los que viven de «su agricultura» (referencia inequívoca a los pequeños campesinos o labradores), tres de las profesiones identificadas con la democracia en la provincia que habían resultado sensiblemente perjudicadas por el anticipo. ${ }^{90}$ Un correligionario de Talavera de la Reina mostró su disconformidad con el adelanto y situó el debate en el plano de la dialéctica derechos-obligaciones, al considerar «ridículo» que tuviesen que sufragar el empréstito aquellos ciudadanos que superasen un margen de 40 reales de contribución mientras que sólo aquellos que rebasaran el umbral de los 400 go-

${ }^{86}$ En relación al papel desempeñado por la religión como instrumento utilizado por las clases propietarias para infundir obediencia, sumisión y disciplina (aspectos criticados por algunos socialistas como Pi) en aras de un progreso material y moral pretendidamente general, consultar RUZAFA ORTEGA, R.: Antes de la Clase. Los trabajadores en Bilbao y la margen izquierda del Nervión, 1841-1891, Bilbao, Universidad del País Vasco, 1998, pág. 210.

87 La Democracia, 1-XII-1865.

88 La Democracia, 13-IV-1864.

89 VALLEJo PousADA, R.: Reforma tributaria y fiscalidad sobre la agricultura en la España liberal, 18451900, Zaragoza, Prensas Universitarias, 2001, pág. 181.

90 El Pueblo, 14-II-1865. 
zaran de derechos políticos. ${ }^{91}$ La lucha por la equiparación entre derechos y obligaciones se convertía en uno de los argumentos centrales de la democracia en el abrupto camino por la implantación del sufragio universal. ${ }^{92}$

El testigo fue recogido por Francisco Córdoba y López en tres artículos publicados en La Democracia consagrados a la crítica de la normativa electoral de 1865. Titulados La nueva Ley Electoral, constituyeron un decidido alegato a favor del sufragio universal, y, por ende, de la Constitución de 1812. Según Córdova y López, la evaluación de la nueva legislación electoral constituía el mejor barómetro para calibrar el espíritu y tendencias del gobierno que la promulgó. Al respecto concluyó tajante, resultaba injusta, inadmisible y arbitraria, al establecer privilegios y conceder la participación política a un reducido número de ciudadanos. ${ }^{93}$ Todas las leyes electorales posteriores a la establecida en la Constitución de 1812, a la cual califica significativamente de esencialmente democrática, adolecieron del mismo defecto, exigir como requisito previo al derecho a voto un determinado nivel de renta. Además vinieron acompañadas por una complementaria administración absorbente y centralizadora, personificada en las figuras del gobernador y el alcalde, que había coartado la autonomía del individuo y de la municipalidad ${ }^{94}$ En el tercero de los artículos incidió en la desigualdad que supuso conceder la plenitud de los derechos políticos en virtud de la posesión de un determinado nivel de renta 0 «capacidad»:

«¿Por qué en vez de fijar la base de este derecho en una cuota no lo hizo en la de la instrucción del ciudadano, para alentar de esta manera, dando disposiciones que coadyuvasen a ello, la enseñanza del pueblo? ¿Por qué no concedió también el derecho a votar a los que supiesen leer y escribir?

La nueva ley no desea la capacidad del elector, y tanto es así, que las capacidades de la nación han sido postergadas a la preocupación por los intereses...la reforma electoral no quiere la instrucción... „\$5

Era una referencia inequívoca al sistema estipulado por la Constitución de 1812 , en el cual esa cuota mencionada en el fragmento anterior era sustituida por la implantación de la instrucción primaria gratuita, obligatoria por extensión, como soporte de la formación de la ciudadanía. ${ }^{96}$ Una vez desglosados los aspectos «negativos» de la normativa electoral lanzó la siguiente pregunta: ¿Es admisible para los partidos liberales, digamos la palabra, revolucionarios? La res-

91 La Democracia, 1-II-1865.

92 En relación a la escisión de las clases medias en base al «corte político» operado por el sufragio censitario, consúltese FUENTES, J. F.: «Clase media y burguesía en la España liberal (1803-1874): ensayo de conceptualización», Historia Social, 17 (1993), págs. 49-50.

93 La Democracia, 2-VIII-1865.

94 La Democracia, 3-VIII-1865.

95 La Democracia, 4-VIII-1865.

96 Cfr. CoRREA, M.: «La ilusión identitaria: la educación como construcción del ciudadano», en Ramos SANTANA, A. (coord.): La ilusión constitucional: pueblo, patria, nación. De la llustración al Romanticismo, Cádiz, América y Europa ante la modernidad. 1750-1850, Cádiz, Universidad, 2004, págs. 188-189; y PIQUERAS ARENAS, J. A.: El taller y la escuela, Madrid, Siglo XXI, 1988, pág. 200. 
puesta era evidente, entre el lema del «todo o nada» estandarte de los abstencionistas, dejó claro que dichas reformas no constituían ese todo, de ahí que recomendase a la democracia el retraimiento, y, de forma encubierta, la vía revolucionaria. ${ }^{97}$

No obstante, de nuevo el peligro de escisión acompañó el debate de la política abstencionista en 1865. Desde Belmonte se lamentaron las disensiones que tuvieron como escenario el seno del partido, motivadas por los titubeos de un sector del partido encabezado por Nicolás María Rivero con volver a la participación política. Partiendo del respeto a la autonomía de los miembros del partido, realizaron una llamada a la unión de todos los correligionarios bajo el pretexto de que las circunstancias que habían determinado dos años antes adoptar la resolución de abandonar la vía política (falseamiento electoral, exclusivismo partidista de la Corona, etc...), continuaban con plena vigencia. ${ }^{98}$ La libertad de opinión y la autonomía que defendieron sus correligionarios conquenses contrastó con la disciplina y subordinación a los designios que emanasen del Comité Central defendida desde Guadalajara y Alcaraz (Albacete). ${ }^{99}$ En Ciudad Real la conducta a seguir fue sometida a deliberación durante la reunión celebrada en la capital con el objetivo de elegir el Comité Provincial. La inmensa mayoría se pronunció a favor de la continuidad. ${ }^{100}$ Incluso dos demócratas toledanos se ofrecieron como redactores a Eugenio García Ruiz, director de El Pueblo, tras la marcha de algunos de sus colaboradores una vez que el diario decidió continuar con la política de retraimiento. ${ }^{101}$

No obstante este abrumador consenso en torno al abandono de las urnas, esta estrategia, aunque válida, resultó incompleta a los ojos de muchos correligionarios que implícitamente abogaron por la vía insurreccional. Así se desprende del comunicado emitido por el Comité de Toledo, en el cual a la par que explicitó su apoyo a la abstención, evidenció su insuficiencia toda vez que no desaparezcan los obstáculos consabidos. ${ }^{102}$ Era una clara alusión a Isabel II, todos los esfuerzos serían inútiles mientras la soberana continuase en la cúspide del entramado político exclusivista que amparó. Un testimonio en la misma dirección fue elevado por un demócrata de Sonseca (Toledo) incitando a no quedarse con los brazos cruzados e ir hasta el término que dicha política nos determina y concluir de este modo de una vez con la tiranía. ${ }^{103}$ El horizonte al que se refería no era otro que el de la revolución, la misma meta que tuvo en mente un republicano de Caudete que ex-

97 La Democracia, 3-VIII-1865.

98 La Democracia, 1-XI-1865.

99 El Pueblo, 5-VIII-1865 y La Democracia, 29-X-1865.

100 El Pueblo, 28-IX-1865. Juan Bautista Pérez, representante del Comité de Almagro y único miembro que se pronunció a favor de abandonar la abstención, acató el sentir mayoritario de sus compañeros de partido y fue elegido para representar al Comité Provincial en Madrid, posicionándose con el bloque individualista encabezado por Castelar, El Diario Español, 6-XII-1865.

101 El Pueblo, 20-IX-1865.

102 La Democracia, 30-VIII-1865.

103 El Pueblo, 10-X-1865. 
hortó a sus correligionarios a salir del quietismo y letargo en que habían caído merced a una política de retraimiento que, si bien había cumplido con importantes objetivos, pues han tomado incremento nuestras filas, resultó insuficiente:

«Somos partido de movimiento, de lucha y de combate por la libertad que apetecemos y nos falta, y por el precioso don que siempre hemos defendido y que tantos sacrificios penosos nos cuesta; y no estamos para dormitar...ni para continuar de simples espectadores, parásitos, sufriendo el yugo de los odiosos déspotas y bajo la tiranía» 104

\section{LA ESTRATEGIA REVOLUCIONARIA}

A partir de comienzos de 1866 los acontecimientos se precipitan. La relativa tolerancia que había marcado la campaña electoral del otoño-invierno de 1865 se tornó en una feroz represión gubernamental con el inicio del nuevo año. La organización institucional que había desplegado el partido durante los últimos años, a través de comités y órganos periodísticos, pasó de nuevo a la clandestinidad y se volcó de lleno en los trabajos revolucionarios. Como censuró uno de los condescendientes biógrafos de O'Donnell, los comités eran clubs organizados para ir a la revolución. ${ }^{105}$

Resulta una tarea enmarañada deslindar con claridad las actividades subversivas protagonizadas por demócratas de aquellas de carácter exclusivamente progresista en los distintos levantamientos que se sucedieron a partir de inicios de 1866. ${ }^{106}$ En enero de este mismo año, los hermanos Merino, promotores de diferentes levantamientos republicanos desde 1848 en la zona de Despeñaperros, se refugiaron en Sierra Morena junto a algunos compañeros para escapar de la represión desencadenada tras el fracaso de la intentona progresista de ese mismo mes, con la cual afirmaron no haber tenido relación alguna. ${ }^{107}$ Otros correligionarios decidieron implicarse activamente en las actividades conspirativas. Uno de ellos fue el secretario del Ayuntamiento de Retuerta (Ciudad Real), quien se unió en enero de 1866 a las tropas de Prim a su paso por la localidad en su retirada hacia Portugal. ${ }^{108}$ Mayor complejidad revistieron las actividades conspirativas desarrolladas por un grupo de revolucionarios de Ciudad Real a la altura de julio de 1867, quienes a través de un enlace enviado a Madrid, coordinaron sus planes subver-

104 El Pueblo, 20-IX-1865.

105 Navarro y Rodrigo, C.: O'Donnell y su tiempo, Madrid, Imprenta de la Biblioteca Universal Económica, 1869, pág. 237.

106 Algo similar había ocurrido con las ramificaciones que tuvo en La Mancha el plan revolucionario frustrado por los sucesos de la Noche de San Daniel en abril de 1865; Roel, E.: Op. Cit., pág. 302.

107 La Democracia, 16-VI-1866.

108 AHPAB, Audiencia criminal, «Rebelión y sedición no cantonal ni carlista», caja 64, causa num. 5. Su adhesión a los sublevados motivó su procesamiento a su regreso a la localidad toledana de Alameda de la Sagra en julio de 1866, donde al parecer también tomó parte en otro intento de levantamiento posterior. Finalmente se acogió a un indulto promulgado en enero de 1868. 
sivos con los núcleos que operaron en la capital, finalmente descubiertos y abortados por las autoridades gubernamentales. ${ }^{109}$

Las encubiertas tramas sediciosas coexistieron con una cascada de manifestaciones públicas de descontento que levantaron acta de la dilatada oposición que despertaron los últimos ministerios moderados, y de forma especial, su principal valedora, Isabel II. Resulta sintomático al respecto el grito de Viva Prim y muera la reina proferido durante una romería por un grupo de vecinos en Campillo de la Sierra (Cuenca) tras prohibir las autoridades locales la celebración de un tradicional juego de azar. Condenados por un delito de rebelión, fueron indultados un año más tarde por la Junta Revolucionaria de la provincia, al comprender que su actitud constituyó el grito de libertad anticipado al que ha dado la nación. ${ }^{110}$

Toda esta serie de movimientos subversivos supusieron un antecedente del generalizado movimiento de oposición extendido por toda la geografía peninsular a raíz del levantamiento iniciado en Cádiz por la coalición de fuerzas revolucionarias. En las áreas urbanas las tentativas contaron con la dificultad de enfrentarse a unas fuerzas gubernamentales concentradas y prestas para reprimir cualquier intentona subversiva, mientras que en las zonas rurales, la dispersión de las fuerzas de orden público y la mayor movilidad y facilidad para la dispersión favorecieron la extensión del movimiento opositor de la ciudad al campo.

Los telegramas enviados por el Gobernador Militar de Ciudad Real al Ministro de la Guerra permiten reconstruir la actividad de al menos nueve partidas revolucionarias que, en esta provincia y en la vecina de Toledo, se formaron a partir del día 22 de septiembre. ${ }^{111}$ Félix Sánchez de Molina, militar progresista organizador del levantamiento contra el Gobierno de Sartorius en Ciudad Real en 1854, encabezó la partida sublevada en su localidad natal, Brazatortas (Ciudad Real), ${ }^{112}$ mientras que el coronel demócrata Ramón Solá Barrón fue el encargado de dirigir la formada en Menasalvas según las instrucciones que había recibido de sus correligionarios de la capital toledana. ${ }^{113}$

Conscientes de su debilidad frente a las fuerzas gubernamentales, sus actividades se centraron en las zonas alejadas a los principales núcleos de población,

109 Alvarado, J.: «La sección de orden público a fines del reinado de Isabel II: la represión política a través de los ficheros policiales reservados", en Alvarado, J.: Poder, economía, clientelismo, Madrid, Marcial Pons, 1997, pág. 161.

110 AHPAB, Audiencia criminal, «Rebelión y sedición no cantonal ni carlista», caja 63, causa num. 20. En la misma causa se menciona la existencia de partidas revolucionarias que operaron en la provincia de Cuenca a la altura de 1867, aunque sin aportar más detalles al respecto.

111 Servicio Histórico Militar (Madrid), Sección Orden Público, sig. 5929/13, leg. num. 202. Por orden cronológico, el día 22 de septiembre se formaron las de Bolaños, Carrión de Calatrava y Miguelturra (Ciudad Real); el día 24 en Menasalvas (Toledo), el día 25 en Villanueva de San Carlos (Ciudad Real) compuesta de cuarenta infantes y diez caballos-y en Mestanza (Ciudad Real) -la más numerosa, formada por sesenta infantes y cinco caballos-; el día 27 en Brazatortas — con una fuerza de 35 a 40 hombres - y Piedrabuena (Ciudad Real) — con unos 25 integrantes entre sus filas-.

112 Boletín Oficial de la provincia de Ciudad Real, núm. 104, 24-VII-1854.

113 De LA Fuente Monge, G.: Los revolucionarios de 1868. Elites y poder en la España liberal, Madrid, Marcial Pons, 2000, págs. 42 y 47. 
cortando las líneas telegráficas y de ferrocarril con el objetivo de dificultar los últimos esfuerzos represivos de las autoridades. ${ }^{114}$ Sólo dos de ellas mantuvieron un enfrentamiento directo con las autoridades locales; la de Menasalvas, en cuya población y en la vecina de Navahermosa liberaron a un grupo de presos políticos y se apropiaron de caballos, armamento y fondos estatales; y la de Bolaños, identificada por las autoridades con una banda de delincuentes en un decidido intento por despolitizarla. ${ }^{115}$

La labor llevada a cabo por pequeñas partidas rurales dirigidas por reconocidos cabecillas y que no superaron el centenar de paisanos - según los denominaron las autoridades militares-, no puede ser infravalorada dentro de un movimiento opositor más amplio que no puede reducirse, como tradicionalmente se ha realizado, a la victoria militar de Alcolea. Muchos de estos protagonistas pasaron a formar parte de las juntas que jalonaron la región tras años de lucha clandestina y represión, aunque un análisis de esta cuestión desbordaría los objetivos de este trabajo. El 30 de septiembre eran destrozados en Albacete todos los retratos de Isabel II que existían en las instituciones públicas de la capital, un epílogo sumamente simbólico al régimen político derribado, cuya opresión condensaron los despedazados lienzos de la soberana. ${ }^{116}$

Todos estos datos autorizan a derribar la imagen arrojada por esa serie de tópicos generalizantes que habían presentado a estas provincias como una verdadera intemperie en relación a la ideología democrática. Este hecho tampoco puede inducir al error de presentar una región con un fuerte arraigo de la cultura política republicana, al contrario, como certeramente afirmó un demócrata de Socuéllamos (Ciudad Real), en estas tierras a la altura de 1865 todavía se encontraba en germen. ${ }^{117}$

${ }^{114}$ En concreto cortaron el telégrafo a la altura de Viso del Marqués y la línea de ferrocarril en las proximidades de Almuradiel (Ciudad Real), sabotaje que retrasó el envío de tropas que desde Madrid fueron destinadas a Andalucía para combatir a los sublevados.

115 Villena Espinosa, R.: El Sexenio Democrático..., Op. Cit., págs. 253-254.

116 La Musa, 4-X-1868.

117 La Democracia, 29-X-1865. 